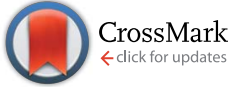

Cite this: RSC Adv., 2017, 7, 16931
Received 24th December 2016 Accepted 11th March 2017

DOI: $10.1039 / c 6 r a 28648 h$

rsc.li/rsc-advances

\section{Fabrication and characterization of nanocomposite film made from a jackfruit filum polysaccharide incorporating $\mathrm{TiO}_{2}$ nanoparticles by photocatalysis $\uparrow$}

\author{
Bei Jin, $\$^{*}$ Xiangzhong Li, $\$$ Xiaosong Zhou, Xuan Xu, Hailin Jian, Mulan Li, Keqi Guo, \\ Jinmin Guan and Shanglong Yan
}

Jackfruit filum polysaccharide (JFPS) was extracted and confirmed to contain neutral and acidic polysaccharides, largely composed of acidic polysaccharides. Biodegradable JFPS-titanium dioxide $\left(\mathrm{TiO}_{2}\right)$ nanocomposite films were fabricated using the solvent casting method combined with photocatalysis. The result of scanning electron microscopy (SEM) shows a uniform distribution of $\mathrm{TiO}_{2}$ nanoparticles into the gelatin matrix. Incorporation of $\mathrm{TiO}_{2}$ into the JFPS matrix significantly decreased the transparency, moisture content and total soluble matter. Surface hydrophobicity also decreased, the mechanical properties and thermal stability of the JFPS films improved. The JFPS/TiO 2 nanocomposite films exhibited strong antibacterial activity against Escherichia coli and Staphylococcus aureus. The films incorporated with $3 \%(\mathrm{w} / \mathrm{w}) \mathrm{TiO}_{2}$ showed the best mechanical properties and thermal stability, as well as excellent antimicrobial activity against Escherichia coli (78.9\%) and Staphylococcus aureus (60.57\%). The data of Fourier transform infrared spectra (FTIR) and X-ray diffraction (XRD) indicate that photocatalysis might contribute to the formation of the strong interfacial interaction between the JFPS matrix and $\mathrm{TiO}_{2}$ nanoparticles. Finally, these results demonstrated the feasibility of introducing photocatalysis to prepare nanocomposite films, and it is of significance in utilizing the $\mathrm{JFPS}$ and $\mathrm{TiO}_{2}$ to produce biodegradable nanocomposite films as packaging material in food and non-food industries.

\section{Introduction}

There has been a growing interest in recent years to develop active packaging to improve food safety and shelf life. Meanwhile, edible active packaging is the main focus of current food packaging research and developments due to its abilities to delay oxidation, inhibit microbial growth and control respiration rate. ${ }^{1}$ So antioxidant and antimicrobial packaging is an important kind of active packaging and a very promising food preservation technique for extending food product shelf life. The commonly used base materials for edible films are polysaccharides, proteins and lipids. ${ }^{2}$ Especially, polysaccharides with good film forming characteristics and relatively good barrier properties are commonly used for edible films. ${ }^{3}$

Jackfruit (Artocarpus heterophyllus Lam.) originated in India and now is very popular throughout southeast Asia. Jackfruit is

School of Chemistry and Chemical Engineering, Institute of Physical Chemistry, Development Center for New Materials Engineering \& Technology in Universities of Guangdong, Lingnan Normal University, Zhanjiang 524048, PR China. E-mail: jinb@lingnan.edu.cn; Fax: +86-759-3183205; Tel: +86-759-3183205

$\dagger$ Electronic supplementary information (ESI) available. See DOI: 10.1039/c6ra28648h

\$ These authors contributed equally to this work. a medium-size evergreen tree that bears high yields of the largest known, succulent, aromatic, and flavorful fruit. ${ }^{4}$ Recently, jackfruit has attracted much attention due to its potential beneficial physiological activities, such as free radical scavenging, anti-microbial, anti-inflammatory, anticariogenic, antineoplastic, and hypoglycemic properties. ${ }^{5}$ Jackfruit seeds and other inedible portion discarded as waste are about $70 \%$ of whole plant and usually cause environmental pollution. As a byproduct, jackfruit filum contains redundant functional components such as polysaccharides, carotenoids and flavonoids which were believed to be closely associated with their biological activity. ${ }^{6}$ Extracting polysaccharide is a good way of using jackfruit filum. However, information about the films prepared from jackfruit filum polysaccharide is scarce.

Until now, for protein-rich and unsaturated fatty acid-rich foods, the poor mechanical and barrier properties as well as the limited antioxidative and antimicrobial activities of pure polysaccharide films do not satisfy the needs of the consumers. ${ }^{7}$ Therefore, the research works have been focused on the improvement of such properties by reinforcing biopolymers films with nanocomposite technology. ${ }^{8}$ Among them, titanium dioxide $\left(\mathrm{TiO}_{2}\right)$ nanoparticles have drawn much attention in food packaging and biomedical applications because they are cheap, 
nontoxic and will provide protection against foodborne microorganisms as well as good heat stability. ${ }^{9}$ However, $\mathrm{TiO}_{2}$ particles are easy to aggregate and their incorporated materials usually lead to low stability and the reduction of film physical properties. ${ }^{10}$ Therefore, it is in high demand to develop highly effective green processing procedure to prepare novel active blend film incorporated with $\mathrm{TiO}_{2}$.

There is a growing scientific interest in the influence of photocatalysis on synthesis of compounds with improved properties. Photocatalysis provides a green chemical route for organic functional group transformation under mild conditions. In the past two decades, it has been successfully applied to organic synthesis such as hydroxylation of aromatic, oxidation of amine and carbonylation. ${ }^{11}$ Moreover, photocatalysis could be also used in the preparation of $\mathrm{TiO}_{2}$ nanocomposite material to improve antibacterial activity. ${ }^{12}$ However, to date, there is little information available on the fabrication of polysaccharides $/ \mathrm{TiO}_{2}$ blend film obtained by photocatalysis.

In this work, we developed novel active packaging film made from a jackfruit filum polysaccharide incorporating $\mathrm{TiO}_{2}$ nanoparticles by photocatalysis. Moisture content, microstructure, and mechanical properties of the films were investigated. Antibacterial property of the films was evaluated. Finally, possible interactions between $\mathrm{TiO}_{2}$ nanoparticles and polysaccharides would be considered in the development of active packaging.

\section{Experimental}

\section{Extraction and characterization of jackfruit filum polysaccharide (JFPS)}

The jackfruit filum polysaccharide was fabricated by a method modified from that reported in ref. 13. Briefly, the jackfruit filum was dried at $55{ }^{\circ} \mathrm{C}$ for $24 \mathrm{~h}$ and ground to a 30 mesh powder. The jackfruit filum was then extracted with $80^{\circ} \mathrm{C}$ preheated alcohol at a ratio of $1: 4(\mathrm{w} / \mathrm{v})$ for $2 \mathrm{~h}$ in order to remove the soluble monosaccharide and oligosaccharides, which was repeated two more times, and then was evaporated to remove the alcohol. The resulting jackfruit filum powder was further immersed in distilled water (powder : water ratio, $1: 30, \mathrm{w} / \mathrm{v}$ ) under stirring $\left(250 \mathrm{rpm}, 80{ }^{\circ} \mathrm{C}, 3 \mathrm{~h}\right)$ and filtered. The filtrate was centrifuged (8000 rpm, $20 \mathrm{~min}$ ), precipitated with ethanol $95 \%$ (filtrate/ethanol ratio, $1: 2.5, \mathrm{v} / \mathrm{v}$ ), and let it sit overnight, finally the mixtures were centrifuged again. The precipitates were collected, and washed three times with absolute ethanol, and then dried at $40{ }^{\circ} \mathrm{C}$ in a vacuum oven. The content of polysaccharide was determined using phenol- $\mathrm{H}_{2} \mathrm{SO}_{4}$ methods.

The conditions of PC were: the mobile phase was a mixture of ethyl acetate, pyridine, water, and acetic acid ( $5: 5: 3: 1)$; the sugars were identified by spraying $o$-phthalic acid reagent $(1.6 \mathrm{~g}$ of $o$-phthalic acid was dissolved in $100 \mathrm{ml}$ of water saturated $n$ butanol, containing $0.9 \mathrm{ml}$ aniline) onto the paper and heating at $100{ }^{\circ} \mathrm{C}$ for 2 min. ${ }^{14}$

The samples were hydrolyzed with $2 \mathrm{M}$ trifluoroacetic acid (TFA) at $100{ }^{\circ} \mathrm{C}$ for $4 \mathrm{~h}$. One part of the hydrolysate was acetylated and then measured by GC-MS (GC7820A, Agilent, USA) with an HP-5 quartz capillary column $(30 \mathrm{~m} \times 0.25 \mathrm{~mm} \times 0.25$ $\mu \mathrm{m}$ ). The GC conditions were: helium carrier (gas flow rate at

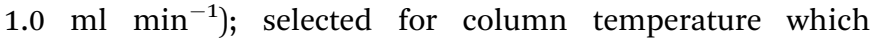
increased from $50{ }^{\circ} \mathrm{C}$ to $250{ }^{\circ} \mathrm{C}$ at the rate of $10{ }^{\circ} \mathrm{C} \mathrm{min}^{-1}$; temperature of the injection port was $260{ }^{\circ} \mathrm{C}$; ion source: EI, $70 \mathrm{eV}$; the molecular weight range: $20-600$.

\section{Film preparation}

To prepare the suspension, different ratios of $\mathrm{TiO}_{2}$ (Degussa, P25) $(0,0.5 \%, 1 \%, 2 \%, 3 \%$ and $4 \% \mathrm{w} / \mathrm{w})$ were dissolved in $50 \mathrm{ml}$ of deionized water and then homogenized in an ultrasonic bath for $15 \mathrm{~min} .10 \%(\mathrm{w} / \mathrm{v})$ JFPS solution was prepared by dissolving the jackfruit filum polysaccharide in distilled water at $80{ }^{\circ} \mathrm{C}$ under stirring for $30 \mathrm{~min}$. After complete dissolution, glycerol ( $3 \mathrm{~g} \mathrm{~g}^{-1}$ of JFPS) as a plasticizer was also added. Afterward, the JFPS solution (prepared according to the above method) was added slowly into the pretreated $\mathrm{TiO}_{2}$ suspension. Then, the mixture was treated at photocatalytic power of $500 \mathrm{~W}$ for $1 \mathrm{~h}$, using a XPA-II photochemical reactor (Nanjing Xujiang Machine-electronic Plant). The resulting solution was degassed under vacuum for $30 \mathrm{~min}$ followed by slow stirring for $4 \mathrm{~h}$ to remove all bubbles. The dried films were peeled from the casting surface and conditioned inside desiccators. To obtain a relative humidity of $55 \%$, desiccators contained saturated magnesium nitrate solution at $25 \pm 1{ }^{\circ} \mathrm{C}$.

\section{Materials characterization}

XRD patterns of the as-prepared samples were recorded on an Xray diffractometer (PANalytical, Netherlands) using Kalfa $\mathrm{Cu}$ radiation. The surface morphology of as-prepared samples was examined by a SEM (LEO1530VP, LEO Company). Fouriertransform infrared spectroscopy (FTIR) spectra were recorded using a Nicolet 6700 spectrophotometer (Thermo Fisher Scientific, USA) thermal properties of jackfruit filum polysaccharide-based films were measured using a thermogravimetric analyzer (SEIKO INSTRUMENTS, Japan). Tensile strength (TS) and elongation at break (EBA) were determined by using a Texture Analyzer (TA.XT2i, Stable Micro Systems, Surrey, England). The surface hydrophobicity of the films was determined with measuring water contact angle by a face contact angle meter (OCA 20, DataPhysics, Germany) according to the method described by Cerqueira et al. ${ }^{15}$ Transparency of films was determined by measuring the percentage of transmittance using a spectrophotometer (Shanghai JINMI Science Instrument Co. Ltd., Shanghai, China) at $600 \mathrm{~nm}$ according to the method of Pérez et al. ${ }^{16}$ with a slight modification. The moisture content (MC) and total soluble matter (TSM) of films was measured according to the method described by Kowalczyk et al. ${ }^{17}$ Film specimens were weighed $( \pm 0.0005 \mathrm{~g})$ and dried in an oven at $105^{\circ} \mathrm{C}$ for $24 \mathrm{~h}$ to a constant weight. The weight loss of each sample was determined, and the moisture content (MC) was calculated as the percentage of water removed from the system. The total soluble matter (TSM) was expressed as the percentage of film dry matter solubilized after $24 \mathrm{~h}$ immersion in water. Each dried sample was shaken in $30 \mathrm{ml}$ of distilled water at $25 \pm 1{ }^{\circ} \mathrm{C}$ for $24 \mathrm{~h}$. Film samples were then removed from the solution and redried at $105{ }^{\circ} \mathrm{C}$ for $24 \mathrm{~h}$ to determine 
solubilized dry matter. Initial dry matter values needed for TSM calculations were obtained from MC measurements for the same film.

\section{Antibacterial activity tests}

The antibacterial activity of films against the bacteria $E$. coli and $S$. aureus was tested using the method described by Wang et al. ${ }^{18}$ $1 \mathrm{ml}$ water solution with bacteria $\left(10^{6} \mathrm{CFU} \mathrm{ml}{ }^{-1}\right)$ was added onto the surface of each film sample. The samples were illuminated with a mercury lamp at room temperature. After $0.5 \mathrm{~h}$, the samples were washed thoroughly with $20 \mathrm{ml}$ of $0.85 \% \mathrm{NaCl}$ solution in order to remove the adhered bacteria in the sterilized Petri dishes. Then $100 \mu \mathrm{l}$ of each bacteria suspension was dispersed on the Agar medium and incubated for $20 \mathrm{~h}$ at $37^{\circ} \mathrm{C}$. The numbers of surviving bacteria on the mediums were counted after incubation. The antibacterial activity was determined as $R(\%)=(B C) / B \times 100 \%$, where $R$ is relative eradication of the bacteria (\%), $B$ is the mean number of bacteria on the control sample, and $C$ is the mean number of bacteria on the analyzed sample.

\section{Statistical analysis}

Statistical data were analyzed using Origin 8.0 and SPSS 16.0. Analysis of variance (ANOVA) with one-way and two-way was carried out. Differences between pairs of means were assessed on the basis of confidence intervals using the Duncan's multiple range tests.

\section{Results and discussion}

The yield of JFPS extraction was $2.87 \%$ (w/w, based on jackfruit filum defatted powder), slightly lower than the $3.91 \%$ yield of jackfruit pulp obtained by Tan et $a .^{6 \boldsymbol{b}}$ PC analysis clearly detected the presence of arabinose, glucose, galacturonic acid and a small amount of galactose in JFPS (Fig. S1 $\dagger$ ). The retention times of four peaks in GC profile were $5.77 \mathrm{~min}, 8.44 \mathrm{~min}$, $8.92 \mathrm{~min}$ and $9.12 \mathrm{~min}$, respectively. The peaks represented the hexa-acetate of D-arabitol, inositol, D-glucitol and D-galactitol, respectively (Fig. S2 $\dagger$ ). GC-MS analysis indicated that neutral polysaccharide component of the JFPS was composed of arabinose, glucose, galactose with a relative molar ratio of $1: 1.56: 1.17$. However, $\mathrm{Zhu}$ et al. reported that the polysaccharide from jackfruit pulp was mainly composed of rhamnose, arabinose, galactose, glucose, xylose and galactose A. ${ }^{6 c}$ The variation in the composition of monosaccharides might depend on the jackfruit tissues and analytic instruments.

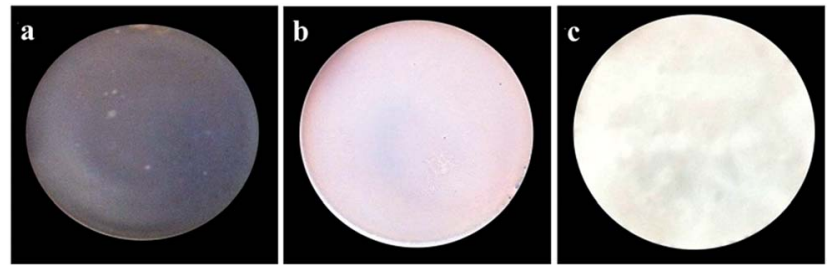

Fig. 1 Photographs of the (a) pure JFPS film, (b) $\mathrm{JFPS} / \mathrm{TiO}_{2}-0.5 \%$ and (c) $\mathrm{JFPS} / \mathrm{TiO}_{2}-4 \%$ nanocomposite films.

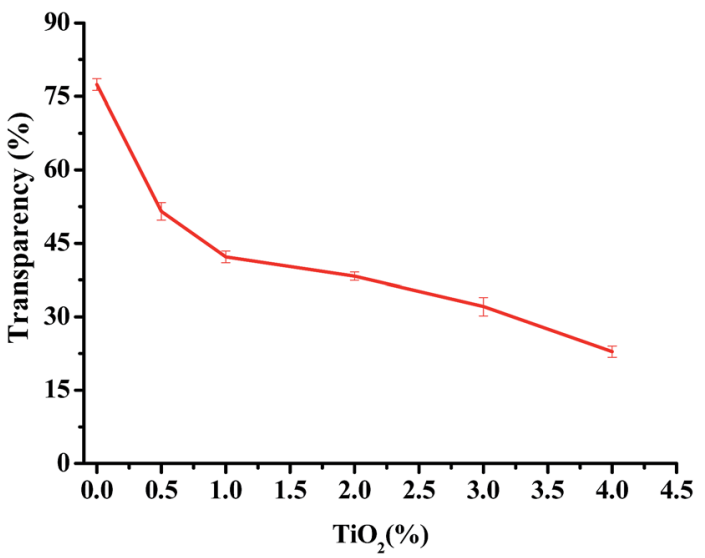

Fig. 2 Effect of $\mathrm{TiO}_{2}$ concentrations on the transparency of $\mathrm{JFPS} / \mathrm{TiO}_{2}$ nanocomposite films.

Table 1 Effect of $\mathrm{TiO}_{2}$ concentrations on moisture content and total soluble matter of JFPS/TiO 2 composite films ${ }^{a}$

\begin{tabular}{llr}
\hline $\mathrm{TiO}_{2} / \mathrm{JFPS}(\mathrm{w} / \mathrm{w}, \%)$ & WC $(\%)$ & \multicolumn{1}{c}{$\mathrm{TSM}(\%)$} \\
\hline 0 & $22.6 \pm 0.01^{\mathrm{a}}$ & $90.2 \pm 0.07^{\mathrm{a}}$ \\
0.5 & $18.8 \pm 0.01^{\mathrm{c}}$ & $83 \pm 0.02^{\mathrm{b}}$ \\
1 & $21.2 \pm 0.04^{\mathrm{b}}$ & $80 \pm 0.05^{\mathrm{b}}$ \\
2 & $21.6 \pm 0.03^{\mathrm{ab}}$ & $68.5 \pm 0.10^{\mathrm{c}}$ \\
3 & $18.3 \pm 0.05^{\mathrm{d}}$ & $67.3 \pm 0.12^{\mathrm{c}}$ \\
4 & $18.9 \pm 0.04^{\mathrm{c}}$ & $59.8 \pm 0.15^{\mathrm{d}}$
\end{tabular}

${ }^{a}$ Results for each film are expressed as means \pm standard deviation $(n=$ 3 ). Values in the same column followed by the different letters indicate significantly differences $(p>0.05)$ according Duncan's multiple range test.

The photographs of one pure JFPS film, JFPS/ $\mathrm{TiO}_{2}-0.5 \%$ and (c) $\mathrm{JFPS} / \mathrm{TiO}_{2}-4 \%$ nanocomposite films are shown in Fig. 1. Films formulated with and without $\mathrm{TiO}_{2}$ were clear and easy to peel from the casting plate. Films became less transparent and flexible with increased $\mathrm{TiO}_{2}$ concentration, but maintained a smooth surface without cracks or pores. Increasing the $\mathrm{TiO}_{2}$ concentration more than $4 \%(\mathrm{w} / \mathrm{w})$ makes the JFPS films nonhomogeneous. Moreover, the pure JFPS film was transparent with a light pink colour. The JFPS/ $\mathrm{TiO}_{2}-0.5 \%$ was translucent with a light pink color. The JFPS/TiO $2-4 \%$ was opaque with a white color. Transparency of the film is an important attribute, which influences the antioxidant capacity and acceptability of food in packaging systems. As shown in Fig. 2, with the addition of $\mathrm{TiO}_{2}$, the transparency of JFPS films significantly decreased, and that the transparency reached to a minimum level $(22.9 \%)$ at concentration of $4 \% \mathrm{TiO}_{2}$ nanoparticle (Fig. 2). This behavior can be probably due to nonuniform distribution of nanoparticles. Similar results were also reported by Zolfi et al. in kefiran-whey protein film incorporated with $\mathrm{TiO}_{2} \cdot{ }^{19}$ The change in transparency may be caused by the presence of $\mathrm{TiO}_{2}$ in films. $\mathrm{TiO}_{2}$ could increase the whiteness of film at higher amounts, indicating that $\mathrm{TiO}_{2}$ might increase in crystallinity and decrease in amorphous regions in structure of films. 


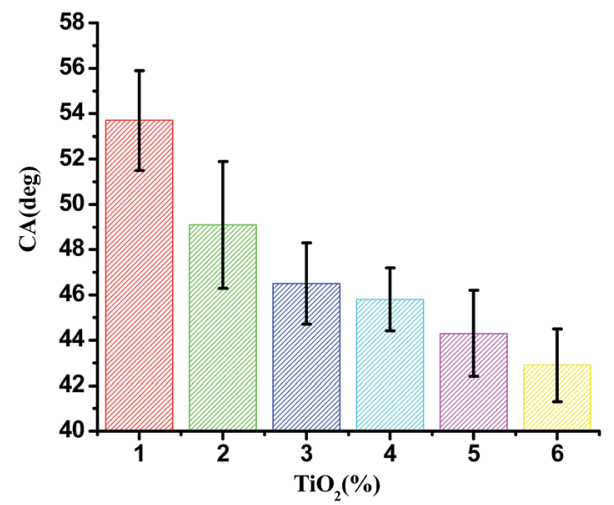

Fig. 3 Effect of $\mathrm{TiO}_{2}$ on the contact angle of $\mathrm{JFPS} / \mathrm{TiO}_{2}$ nanocomposite films.

Moisture content of the film is a very important attribute for food packaging application because packaging films have to maintain moisture levels within the packaged product. Table 1 shows MC values for films with different levels of $\mathrm{TiO}_{2}$ related to the control film. JFPS films incorporating $\mathrm{TiO}_{2}$ had slightly lower MCs than the control films, whereas no regular variation of MC was observed between the JFPS/ $/ \mathrm{TiO}_{2}$ films with different levels of $\mathrm{TiO}_{2}$. Previous studies reported that incorporation of the $\mathrm{TiO}_{2}$ content of kefiran-whey protein isolate films also reduced moisture content in biocomposite films. ${ }^{20}$ Similarly, total soluble matter of JFPS films generally decreased with an increase in $\mathrm{TiO}_{2}$ nanoparticles content. These results were attributed to possible force between JFPS molecules and $\mathrm{TiO}_{2}$ nanoparticle, which reduced availability of hydroxyl groups in JFPS to interact with water.

Contact angle $(\theta)$ of water with the film surface was used to evaluate the surface hydrophobicity of the film. The contact angle of JFPS films as a function of nanoparticle contents were shown in Fig. 3. The contact angle of pure alginate film was $53.7^{\circ}$, since the JFPS film is hydrophilic in nature. Moreover, the contact angle of JFPS film decreased with $\mathrm{TiO}_{2}$ incorporation and reduced to $42.9^{\circ}$ in $\mathrm{JFPS} / \mathrm{TiO}_{2}-4 \%$ nanocomposites, which was mainly related to the increase in roughness of composite films, which was further confirmed by SEM. Other researchers

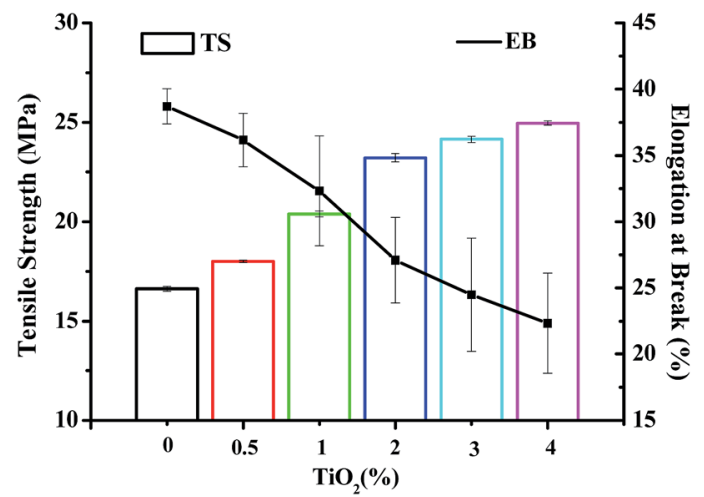

Fig. 4 Mechanical properties of $\mathrm{JFPS} / \mathrm{TiO}_{2}$ nanocomposite films reinforced with different concentrations of $\mathrm{TiO}_{2}$. reported similar results on the effects of nanoparticles on hydrophobicity of alginate and carboxyl methyl cellulose. ${ }^{\mathbf{2 1 2 2}}$

Mechanical properties of a bionanocomposite material are highly dependent on the interfacial interaction between the nanofiller and biocomposite matrix. ${ }^{23}$ Tensile strength (TS) and elongation at break (EBA) of JFPS film and different contents of $\mathrm{TiO}_{2}$ nanocomposite film are shown in Fig. 4. Compared with JFPS film, TS of nanocomposite film increased significantly, EB decreased significantly with the increasing concentration of $\mathrm{TiO}_{2}$, which was in accordance with above MC analysis. These data indicated that the decreased moisture content would reduce the flexibility of the films. What's more, $\mathrm{TiO}_{2}$ nanoparticles could promote mechanical properties of JFPS film because $\mathrm{TiO}_{2}$ might strengthen the interfacial interaction through electrostatic attraction, hydrogen bonds and $\mathrm{Ti}-\mathrm{O}-\mathrm{C}$ bond between JFPS matrix and $\mathrm{TiO}_{2}$ nanoparticles induced by photocatalysis which was verified by XRD and FT-IR analysis and improve phase compatibility of JFPS matrix components which resulted in forming a stable three-dimensional polymeric matrix. ${ }^{24}$ Teymourpour et al. also noticed that tensile strength of soluble soybean polysaccharide film increased by $27.3 \%$ after the addition of $5 \% \mathrm{TiO}_{2}$ nanoparticles. ${ }^{25}$

TGA was carried out to investigate the thermal performance of the nanocomposite films. TGA curves of the JFPS and JFPS/ $\mathrm{TiO}_{2}$ films were presented in Fig. 5. The TGA curves of the films exhibited the weight loss pattern. TGA thermograms show similar behaviours for all studied films, with the presence of three thermal events. The first event (maximum peak occurred at around $65^{\circ} \mathrm{C}$ ) was attributed to water evaporation, which was about $3-8 \%$ of initial weight. The second event (maximum peak from 180 to $240{ }^{\circ} \mathrm{C}$ ) resulted in a weight loss of approximately $40-45 \%$, due to the degradation of glycerol and biopolymer polysaccharides. The degradation with about $45 \%$ of JFPS, nanocomposite films with different $\mathrm{TiO}_{2}$ concentration (0.5-4 $\mathrm{w} / \mathrm{w})$ presented temperature peaks at 227.1, 235.73, 242.51, 247.56, 257.64, and $271.1^{\circ} \mathrm{C}$, respectively. The introduction of nanoparticle $\left(\mathrm{TiO}_{2}\right)$ significantly improved the thermal stability of JFPS films, which can be ascribed to the better thermal stability of $\mathrm{TiO}_{2}$ when compared with JFPS and to good

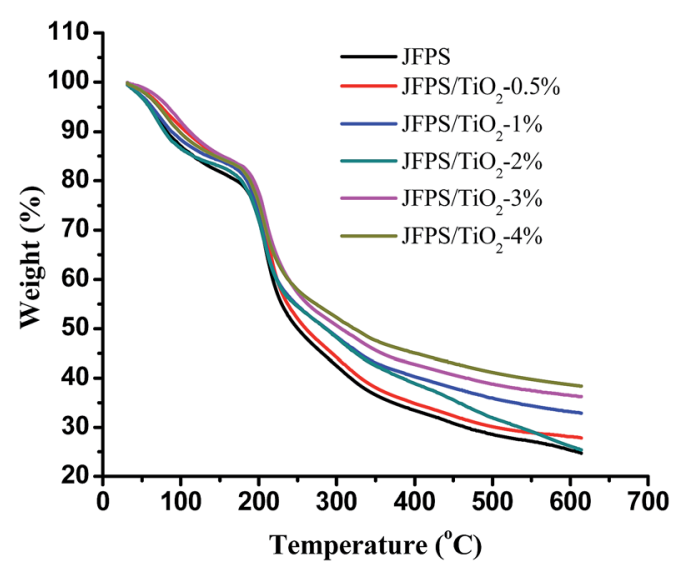

Fig. 5 Thermogravimetry curves of the pure JFPS film and $\mathrm{JFPS} / \mathrm{TiO}_{2}$ nanocomposite films. 
interaction between $\mathrm{TiO}_{2}$ and JFPS. The third thermal event was observed around $300-350{ }^{\circ} \mathrm{C}$, which was mainly related with the further oxidization and decomposition of the samples. After the final thermal decomposition, the residuals of pure JFPS, JFPS/ $\mathrm{TiO}_{2}$ nanocomposite films with different $\mathrm{TiO}_{2}$ concentration $(0.5-4 \mathrm{w} / \mathrm{w})$ were $25.3,28.1,26.1,33.1,36.5$ and $38.6 \%$, respectively. This result indicated that photocatalysis might reinforce the interaction between JFPS molecule and $\mathrm{TiO}_{2}$ nanoparticle which contributed to improve the thermal stability of nanocomposite films. As $\mathrm{TiO}_{2}$ is crystalline; its crystallinity decreases the polar character of JFPS and the global water content in JFPS matrix which is agreement with above MC result. Similar results were also by Yang et al. who presented the decomposition onset temperatures of the nanocomposites shifted toward a higher temperature scope with increasing inorganic material content. ${ }^{26}$

Fig. 6 displays XRD data of the pure $\mathrm{TiO}_{2}$ and composite films with different $\mathrm{TiO}_{2}$ concentrations. The pure JFPS film is semi-crystalline in nature and shows a broad diffraction peak at $2 \theta=22.57^{\circ} . \mathrm{TiO}_{2}$ had a significant peaks at $2 \theta=25.3^{\circ}, 37.9^{\circ}$, $47.8^{\circ}, 54.5^{\circ}, 63.1^{\circ}, 69.4^{\circ}$ and $75.2^{\circ}$, which contains both anatase phase and rutile phase. When the concentration of $\mathrm{TiO}_{2}$ nanoparticles in the film was less than $0.5 \%$, XRD pattern was amorphous, but when the concentration increased and reached $2 \%$, the obtained pattern was almost the same as that of the pure $\mathrm{TiO}_{2}$, which was in agreement with the transparency results. This result expressed that the crystal structure of $\mathrm{TiO}_{2}$ was not altered due to the presence of JFPS. Moreover, the intensity of the main characteristic peaks of $\mathrm{TiO}_{2}$ was higher as the concentration of $\mathrm{TiO}_{2}$ in the JFPS matrix increased. Comparison of peaks of the pure JFPS and nanocomposite films showed that the intensity of the peak at $2 \theta=22.57^{\circ}$ was gradually decreased and became border but no displace with the increasing $\mathrm{TiO}_{2}$ concentrations in the nanocomposite matrix. That might be the incorporation of nanoparticles would destroy the intra-molecules forces in the JFPS film such as hydrogen bonds, and then $\mathrm{TiO}_{2}$ nanoparticles can insert and disperse uniformly in the nanocomposite matrix, which strengthen the interaction between nanoparticles and JFPS molecules such as

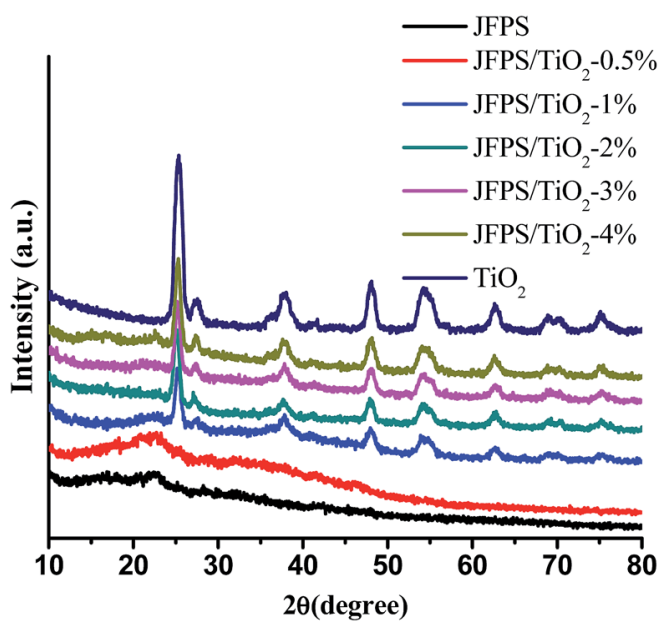

Fig. 6 XRD patterns of the pure JFPS film and $\mathrm{JFPS} / \mathrm{TiO}_{2}$ nanocomposite films.

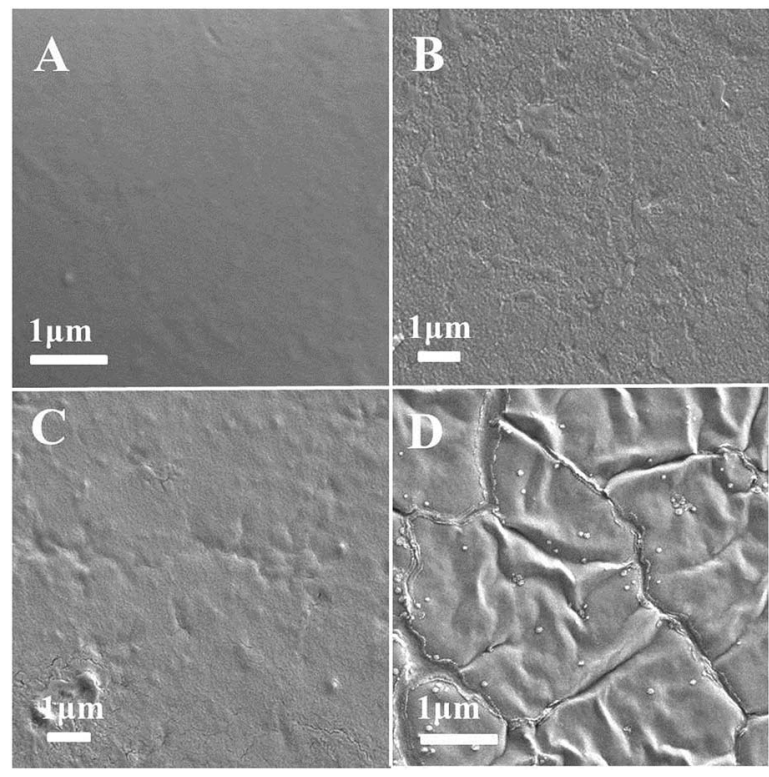

Fig. 7 SEM micrographs of the surfaces of the pure JFPS film and $\mathrm{JFPS} / \mathrm{TiO}_{2}$ nanocomposite films: (A) pure JFPS, (B) $\mathrm{JFPS} / \mathrm{TiO}_{2}-0.5 \%$; (C) $\mathrm{JFPS} / \mathrm{TiO}_{2}-2 \%$; (D) JFPS/ $\mathrm{TiO}_{2}-4 \%$.

Ti-O-C bond induced by photocatalysis which was further confirmed by FT-IR analysis. Similar results have been observed with other $\mathrm{TiO}_{2}$-incorporated nanocomposites such as kefiranwhey protein $/ \mathrm{TiO}_{2}$ and chitosan-whey protein $/ \mathrm{TiO}_{2}{ }^{20,21}$

The morphology of films is a very important characteristic as it could ultimately determine many properties of biodegradable materials. SEM patterns of the JFPS are shown in Fig. 7. The pure JFPS film had a homogeneous and smooth surface structure (Fig. 7A). The granular structure on the surface of composite films appeared when $\mathrm{TiO}_{2}$ particles were incorporated (Fig. 7B-D). The results showed that no significant changes were observed after incorporating $\mathrm{TiO}_{2}$ at the concentrations of $0.5-2 \%$ to bio-composite surface. This result indicated that photocatalyst might prompt the formation of the strong interfacial adherence between the JFPS and nano- $\mathrm{TiO}_{2}$ resulting in a good distribution of $\mathrm{TiO}_{2}$ in the polymeric structure, and was beneficial to the mechanical properties of the nanocomposite films. However, the discontinuous phase and some agglomerates can be observed in the microstructure as $\mathrm{TiO}_{2}$ concentration reached $4 \%$. These results were agreed with XRD analysis. Similar results were reported for the surface micrographs of soluble soybean polysaccharide (SSPS)- $\mathrm{TiO}_{2}$ films containing different nano- $\mathrm{TiO}_{2}$ concentrations. ${ }^{25}$

The FT-IR spectra of neat JFPS and JFPS/TiO ${ }_{2}$ nanocomposite films exhibited distinctive peaks in the range of $4000-400 \mathrm{~cm}^{-1}$ (Fig. 8). Signals at 3420, 2920, 1620, 1400 and $1100 \mathrm{~cm}^{-1}$ were the typical characteristic of polysaccharides. ${ }^{27} \mathrm{~A}$ broad and intense peak at $3416 \mathrm{~cm}^{-1}$ and absorption band at $2936 \mathrm{~cm}^{-1}$ were observed in pure JFPS films which were related to $-\mathrm{OH}$ group and for $-\mathrm{CH}_{3}$ stretching vibrations. In addition, the peaks at 1617 and $1440 \mathrm{~cm}^{-1}$ were assigned to asymmetric and symmetric stretching vibrations of carboxyl groups present in the JFPS. The peaks of 1746 and $1261 \mathrm{~cm}^{-1}$ were attributed to 


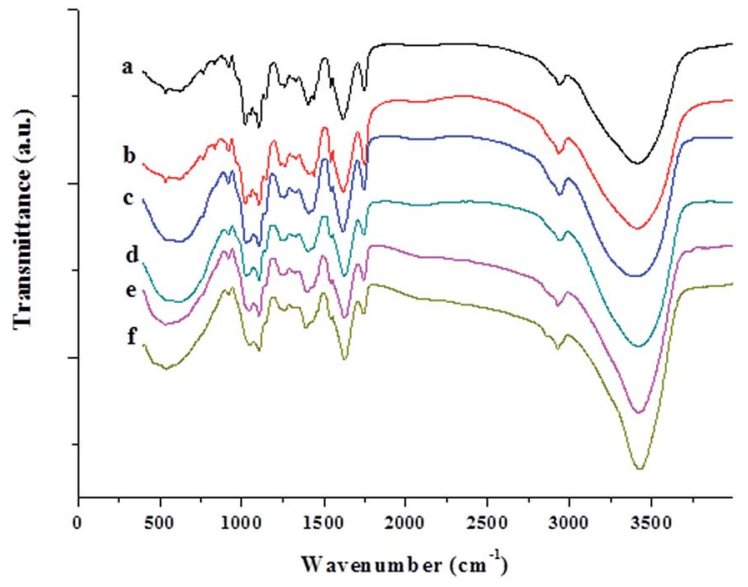

Fig. 8 FTIR spectra of the pure JFPS film and JFPS/TiO 2 nanocomposite films: (a) pure JFPS, (b) JFPS/ $\mathrm{TiO}_{2}-0.5 \%$; (c) $\mathrm{JFPS} / \mathrm{TiO}_{2}-1 \%$; (d) $\mathrm{JFPS} / \mathrm{TiO}_{2}-2 \%$; (e) $\mathrm{JFPS} / \mathrm{TiO}_{2}-3 \%$; and (f) $\mathrm{JFPS} / \mathrm{TiO}_{2}-4 \%$.

the $\mathrm{C}=\mathrm{O}$ and $\mathrm{C}-\mathrm{O}$ component of an ester bond, respectively. The region at $1200-850 \mathrm{~cm}^{-1}$ was assigned to stretching vibrations of $\mathrm{C}-\mathrm{O}, \mathrm{C}-\mathrm{C}$, ring structures and deformation of $-\mathrm{CH}_{2}$ group vibration. Moreover, the absorption peaks around 1100 $\mathrm{cm}^{-1}$ indicate that the sugar rings of the JFPS fractions were pyranose rings. There results indicated that the JFPS might consist of neutral and acidic polysaccharides, largely composed of acidic polysaccharides, which was in accordance with the report described by Zhu et al. ${ }^{6 c}$ As shown in Fig. 8, similar peaks were observed in pure JFPS and $\mathrm{JFPS} / \mathrm{TiO}_{2}$ composite films. However, the intensity of the peak at $3416 \mathrm{~cm}^{-1}$ increased after composite formation with $\mathrm{TiO}_{2}$, suggesting that the nano- $\mathrm{TiO}_{2}$ interacted with JFPS by the hydrogen bond. Additionally, the intensity of band at $1440 \mathrm{~cm}^{-1}$ decreased and the peak position had red shift and that the intensity of the broad band at 535 $\mathrm{cm}^{-1}$ significantly decreased when $\mathrm{TiO}_{2}$ content exceeded $2 \%$. The findings might be an indirect suggestion of the formation of $\mathrm{Ti}-\mathrm{O}-\mathrm{C}$ bonds between the JFPS and nano- $-\mathrm{TiO}_{2}$ induced by photocatalysis, as shown in Fig. 9. In all, FTIR results confirmed the hydrogen bonding between the JFPS molecules and nanoparticles could increase when incorporated with $\mathrm{TiO}_{2}$ nanoparticles.

The antimicrobial activity of JFPS composite films against bacteria $E$. coli and S. aureus was also tested and the results were presented in Fig. 10. JFPS film without added $\mathrm{TiO}_{2}$ showed fairly low antimicrobial activity, the inhibition rates of JFPS film for $E$. coli and $S$. aureus reached $6.87 \pm 1.44 \%$ and $1.77 \pm 0.46 \%$,

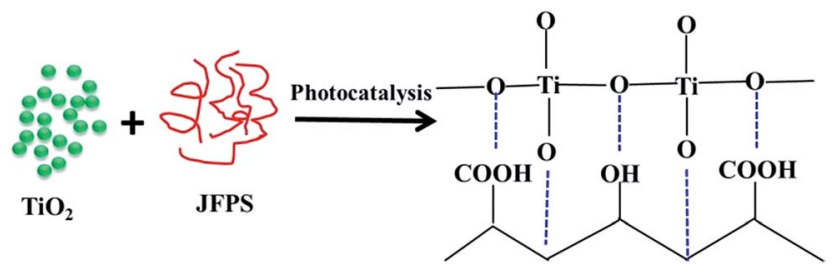

Fig. 9 A scheme illustrating possible interactions between JFPS with $\mathrm{TiO}_{2}$ through photocatalysis.

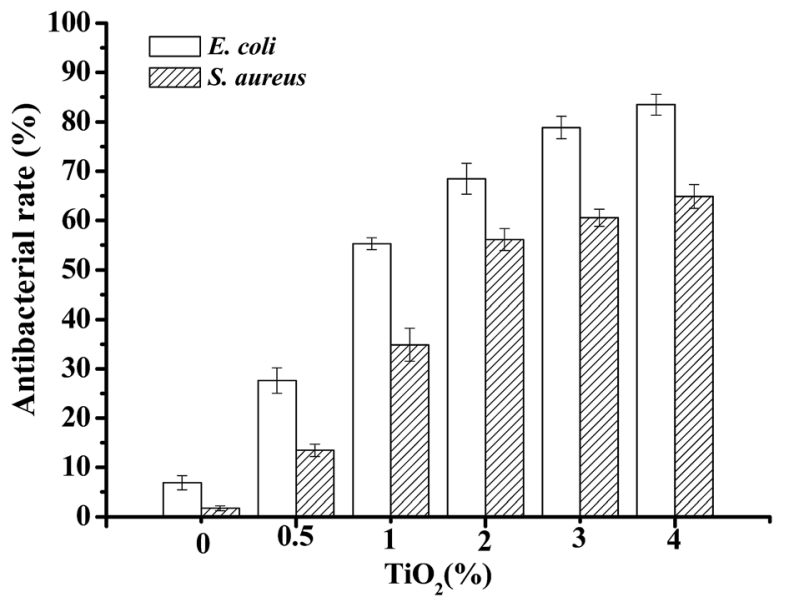

Fig. 10 The antibacterial effects on bacteria E. coli and S. aureus of nanocomposite films with various ratio of $\mathrm{JFPS} / \mathrm{TiO}_{2}$.

respectively. The antibacterial rates increased gradually for the JFPS film reinforced with increasing amounts of $\mathrm{TiO}_{2}$ nanoparticles. $\mathrm{TiO}_{2}$ is considered as antimicrobial agents with a broad spectrum of bacterial and fungal species. It has been believed that $\mathrm{TiO}_{2}$ could generate a strong oxidizing agent, hydroxyl radicals, which lead to lipid peroxidation and leakage of the cell membrane..$^{25}$ This JFPS composite films had high antimicrobial activity due to the intermolecular force between $\mathrm{TiO}_{2}$ and JFPS which led to change in lattice of $\mathrm{TiO}_{2}$ nanoparticle and further generate more reactive oxygen species to inactivate microorganisms by causing cell lysis. In addition, the $\mathrm{TiO}_{2}$ incorporated JFPS composite films demonstrated stronger antimicrobial activity against $E$. coli than $S$. aureus which was opposite to that from the research reported by Teymourpour et $a l . .^{25}$ This might be because cell wall structure of gram negative contains more lipoprotein and phospholipid and less peptidoglycan than that of gram positive bacteria which make the cell membrane more susceptible to attack by hydroxyl radicals leads to lipid peroxidation and protein denaturation. However, further research would be needed to illuminate the interaction between free radical and cell.

\section{Conclusions}

In this study, nano- $\mathrm{TiO}_{2}$ was introduced to JFPS matrixes to prepare novel bionanocomposites using photocatalysis. PC and FT-IR results demonstrated that JFPS might consist of neutral and acidic polysaccharides, largely composed of acidic polysaccharides. The neutral polysaccharide component of JFPS was confirmed to comprise of arabinose, glucose, galactose with a relative molar ratio of $1: 1.56: 1.17$ by GC-MS. Compared with JFPS film, whiteness of nanocomposite film was increased, and transparency was decreased. Moreover, incorporation of the $\mathrm{TiO}_{2}$ improved the mechanical properties and thermal stability of the films made from JFPS. Surface hydrophobicity and water content of JFPS films decreased significantly with the incorporation of $\mathrm{TiO}_{2}$. The SEM and XRD analysis revealed that photocatalysis could promote uniform dispersion of $\mathrm{TiO}_{2}$ in JFPS 
matrix and the formation of homogenous film when $\mathrm{TiO}_{2}$ content was no more than 3\%. The results of FTIR and XRD confirmed that photocatalysis could reinforce intermolecular force between $\mathrm{TiO}_{2}$ and JFPS such as Ti-O-C bonds and hydrogen bond. In addition, the JFPS/ $/ \mathrm{TiO}_{2}$ composite films had stronger antimicrobial activity against $E$. coli than $S$. aureus. The results of this study indicated that the prepared $\mathrm{JFPS} / \mathrm{TiO}_{2}$ composite films with improved properties and antimicrobial activity have a high potential for the use as an active food packaging to increase the food safety and prolong the shelf-life of packaged foods.

\section{Acknowledgements}

This work was financially supported by National Natural Science Foundation of China (No. 31601415), National Natural Science Foundation of Guangdong, China (No. 2016A030307022), the China Spark Program (No. 2014GA780072), Tropical and South China Sea Resources Collaborative Innovation Center of Lingnan Normal University (No. CIL1503), and the Major Program of Lingnan Normal University (No. LZL1501). Finally, we are grateful to Dr Zhang for his support at polysaccharide detection in this study.

\section{Notes and references}

1 C. López-De-Dicastillo, J. Gómez-Estaca, R. Catalá, R. Gavara and P. Hernández-Muñoz, Food Chem., 2012, 131, 13761384.

2 (a) A. Nesterenkoa, I. Alric, F. Silvestre and V. Durrieu, Ind. Crops Prod., 2013, 42, 469-479; (b) B. Ghanbarzadeh, H. Almasi and S. A. Oleyaei, Int. J. Food Eng., 2014, 10, 121130; (c) M. H. Fakharian, N. Tamimi, H. Abbaspour, A. Mohammadi Nafchi and A. A. Karim, Carbohydr. Polym., 2015, 132, 156-163.

3 R. M. Gohil, J. Appl. Polym. Sci., 2011, 120, 2324-2336.

4 S. B. Swami, N. J. Thakor, P. M. Haldankar and S. B. Kalse, Compr. Rev. Food Sci. Food Saf., 2012, 11, 565-576.

5 U. B. Jagtap, S. N. Panaskar and V. Bapat, Plant Foods Hum. Nutr., 2010, 65, 99-104.

6 (a) M. S. Baliga, A. R. Shivashankara, R. Haniadka, J. Dsouza and H. P. Bhat, Food Res. Int., 2011, 44, 1800-1811; (b) Y. F. Tan, H. L. Li, W. Y. Lai and J. Q. Zhang, J. Med. Food, 2013, 16, 663-668; (c) K. X. Zhu, Y. J. Zhang, S. P. Nie, F. $\mathrm{Xu}, \mathrm{S}$. Z. He, D. M. Gong, G. Wu and L. H. Tan, Carbohydr. Polym., 2017, 155, 354-361.

7 (a) A. Wan, Q. Xu, Y. Sun and H. Li, J. Agric. Food Chem., 2013, 61, 6921-6928; (b) P. J. P. Espitia, R. J. Avena-Bustillos, W. X. Du, R. F. Teofilo, N. F. F. Soares and T. H. McHugh, Food Packaging and Shelf Life, 2014, 2, 38-49.

8 (a) A. Arora and G. W. Padua, J. Food Sci., 2010, 75, 43-49; (b) J. George and Siddaramaiah, Carbohydr. Polym., 2012, 87, 2031-2037.
9 Y. Yao, T. Ochiai, H. Ishiguro, R. Nakano and Y. Kubota, Appl. Catal., B, 2011, 106, 592-599.

10 J. J. Zhou, S. Y. Wang and S. Gunasekaran, J. Food Sci., 2009, 74, 50-56.

11 (a) Y. Ide, N. Nakamura, H. Hattori, R. Ogino, M. Ogawa, M. Sadakane and T. Sano, Chem. Commun., 2011, 47, 11531-11533; (b) X. J. Lang, W. H. Ma, Y. B. Zhao, C. C. Chen, H. W. Ji and J. C. Zhao, Chemistry, 2012, 18, 2624-2631; (c) R. F. Chong, J. Li, X. Zhou, Y. Ma, J. X. Yang, L. Huang, H. X. Han, F. X. Zhang and C. Li, Chem. Commun., 2014, 50, 165-167.

12 (a) S. G. Chen, Y. J. Guo, S. J. Chen, H. M. Yu, Z. C. Ge, X. Zhang, P. X. Zhang and J. N. Tang, J. Mater. Chem., 2012, 22, 9092-9099; (b) S. G. Chen, Y. J. Guo, S. J. Chen, Z. C. Ge, H. P. Yang and J. N. Tang, Mater. Lett., 2012, 83, 154-157; (c) S. G. Chen, Y. J. Guo, H. Q. Zhong, S. J. Chen, J. N. Li, Z. C. Ge and J. N. Tang, Chem. Eng. J., 2014, 256, 238-246.

13 C. Qin, K. Huang and H. Xu, Carbohydr. Polym., 2002, 49, 367-371.

14 H. L. Zhang, J. Li, G. Li, D. M. Wang, L. P. Zhu and D. P. Yang, Int. J. Biol. Macromol., 2009, 44, 257-261.

15 M. A. Cerqueira, M. J. Costa, C. Fuciños, L. M. Pastrana and A. A. Vicente, Food Bioprocess Technol., 2013, 7, 1472-1482.

16 L. M. Pérez, M. D. V. Soazo, C. E. Balagué, A. C. Rubiolo and R. A. Verdini, Food Control, 2014, 37, 298-304.

17 D. Kowalczyk, M. Kordowska-Wiater, B. Sołowiej and B. Baraniak, Food Bioprocess Technol., 2015, 8, 567-579.

18 S. Y. Wang, B. B. Zhu, D. Z. Li, X. Z. Fu and L. Shi, Mater. Lett., 2012, 83, 42-45.

19 M. Zolfi, F. Khodaiyan, M. Mousavi and M. Hashemi, Carbohydr. Polym., 2014, 109, 118-125.

20 M. Zolfi, F. Khodaiyan, M. Mousavi and M. Hashemi, Int. J. Biol. Macromol., 2014, 65, 340-345.

21 M. Abdollahi, M. Alboofetileh, M. Rezaei and R. Behrooz, Food Hydrocolloids, 2013, 32, 416-424.

22 M. Quilaqueo Gutiérrez, I. Echeverría, M. Ihl, V. Bifani and A. N. Mauri, Carbohydr. Polym., 2012, 87, 1495-1502.

23 X. Ma, P. R. Chang, J. Yang and J. Yu, Carbohydr. Polym., 2009, 75, 472-478.

24 W. Zhang, J. W. Chen, Y. Chen, W. S. Xia, Y. L. Xiong and H. X. Wang, Carbohydr. Polym., 2016, 138, 59-65.

25 S. Teymourpour, A. M. Nafchi and F. Nahidi, Carbohydr. Polym., 2015, 134, 726-731.

26 M. L. Yang, Y. Z. Xia, Y. X. Wang, X. H. Zhao, Z. X. Xue, F. Y. Quan, C. Z. Geng and Z. H. Zhao, J. Appl. Polym. Sci., 2016, 133, 43489.

27 Q. Li, N. Yu, Y. Wang, Y. Sun, K. Lu and W. Guan, Carbohydr. Polym., 2013, 96, 148-155. 